\title{
Capturing clinically significant eating pathology in adolescence
}

\author{
Rasmus Isomaa, $\mathrm{PhD}^{\star, \star *}$ \\ Anna-Lisa Isomaa, MD*** \\ Mauri Marttunen, MD, DrMedSci ${ }^{\star \star \star \star, \star \star \star \star \star \star}$ \\ Riittakerttu Kaltiala-Heino, MD, \\ DrMedSci, BSc ${ }^{\star \star, \star \star \star \star \star \star \star}$
}

* Åbo Akademi University, Vasa Department of Social Sciences

** Tampere University Hospital, Department of Adolescent Psychiatry

*** Department of Social and Health Care, City of Jakobstad

**** University of Helsinki and Department of Adolescent Psychiatry, Helsinki University Central Hospital

${ }^{\star * \star * *}$ National Institute for Health and Welfare

****** University of Tampere, Medical School

FINLAND

ABSTRACT - Background and Objectives: Several large-scale studies on adolescent mental health have used questionnaire items derived from DSM-IV criteria to assess eating disorders. The aim of the present brief report was to analyse the capacity of self-reported eating disorder symptoms to capture clinically significant eating disorders.

Methods: All pupils in the ninth grade $(N=606$, response rate $98.2 \%$, mean age $=15.4)$ of comprehensive school in a defined area were invited to participate in the study. Adolescents who reported some form of eating pathology $(n=126)$ were invited to an interview (RAB).

Results: Anorexia based on the self-report resulted in a positive predictive value of $60.0 \%$ for lifetime and $20 \%$ for current eating disorder, when compared to the results in the RAB. No case of BN was detected by the RAB, but self-reported BN symptoms were predictive of both EDNOS and subclinical eating pathology.

Conclusions: Self-reported eating disorder symptoms seem to be relatively good predictors of broadly defined eating pathology, but may result in overestimation of clinical conditions.

Received: 30 May 2012

Revised: 28 November 2012

Accepted: 11 December 2012

Funding for this study was provided by the Signe and Ane Gyllenberg foundation, the Otto A. Malm foundation, and the Swedish Cultural Foundation in Finland. 


\section{Introduction}

Eating disorders are serious psychiatric disorders, which alter cognitive function, judgement, emotional stability and restrict the life activities of sufferers ${ }^{1}$. Prevalence and incidence estimates of these disorders have shown substantial variation, largely due to sampling and assessment methods ${ }^{2}$. Studies limited to clinical settings may underestimate true prevalence and large scale, methodologically sound, population based studies are both timeconsuming and expensive ${ }^{3}$. Using questionnaires to assess eating disorders is linked to several potential methodological risks and therefore a two-stage approach using questionnaires for screening and interviews for final assessment is recommended ${ }^{4,5}$. Several broad studies on adolescent mental health have used questionnaire items derived from DSM-IV criteria to assess eating disorders ${ }^{4}$. The validity of this approach has however not received enough attention, especially in the case of adolescents ${ }^{5,6}$. In research eating disorders are generally classified using DSMIV criteria ${ }^{7}$. The classification system has not proven satisfactory and is now undergoing substantial revision ${ }^{8}$. Regarding eating disorders the major problems have been extensive use of the "Not otherwise specified" category and transition between diagnoses during the course of illness ${ }^{9,10}$.

The aim of the present study was to analyse the capacity of self-reported eating disorder symptoms to capture clinically significant eating disorders, i.e. eating disorders of diagnostic severity according to the DSM-IV, by comparing questionnaire data with eating disorder diagnoses obtained by a semi-structured interview.

\section{Methods}

The present study is part of a larger study on the epidemiology of eating disorders (ED) among adolescents in western Finland ${ }^{11}$.

\section{Participants and procedure}

All pupils in the ninth grade (mean age $=$ $15.4, S D=0.3$ ) of comprehensive school, the nine-year basic education in Finland, in the Jakobstad region were invited to participate in the study. The region is part of the Ostrobothnia district on the west coast of Finland. The Jakobstad region with a population of approximately 40,000 inhabitants comprises two small cities and two rural areas. A questionnaire regarding mental health, mental health problems, health behaviour, and life circumstances was distributed to a total of 606 adolescents (318 males and 288 females) in their classrooms during a normal school lesson in the autumn of 2004. The response rate in the study was $98.2 \%$. (98.3\% for girls and $98.1 \%$ for boys) The purpose of the study was to assess eating disorders and related mental health problems in adolescence.

Adolescents who, in addition to dieting, reported at least one other DSM-IV criterion for anorexia nervosa (AN), or, in addition to bingeing, reported at least one other DSM-IV criterion for bulimia nervosa $(\mathrm{BN})$ were invited to a semi-structured interview. Participants who reported previous history of, suspicion of, or treatment for an ED were also invited to an interview.

Informed consent was provided by all participants. For participants under the age of fifteen, parental consent was obtained. 


\section{Measures}

The questionnaire included items derived from DSM-IV diagnostic criteria for eating disorders (Figure 1). Eating disorders were assessed in personal interviews, to which par- ticipants were invited based on their answers to questionnaire items. Additionally, all the participants' height and weight were measured at school during the academic year 2004-2005 and for those participating in the interviews individual growth curves were obtained.

\begin{tabular}{|c|c|c|}
\hline \multirow[t]{4}{*}{ Anorexia nervosa } & AN1 & $\begin{array}{l}\text { Did you ever on purpose reduce your weight several kilograms } \\
\text { or deliberately keep your weight low? } \\
\text { In addition 1-3 of the following questions: }\end{array}$ \\
\hline & AN2 & Did you then fear gaining weight or becoming fat? \\
\hline & AN3 & $\begin{array}{l}\text { Did you feel fat even though family and friends were of the quite } \\
\text { opposite opinion? }\end{array}$ \\
\hline & AN4 & (when dieting) Did you then stop menstruating? \\
\hline \multirow[t]{6}{*}{ Bulimia nervosa } & BN1 & $\begin{array}{l}\text { Did you ever repeatedly binge a lot of food in a short time } \\
\text { (for example, two hours)? }\end{array}$ \\
\hline & & In addition 1-4 of the following questions: \\
\hline & $\mathrm{BN} 2$ & Were you afraid of losing control of eating while bingeing? \\
\hline & $\mathrm{BN} 3$ & Did you binge at least twice a week for at least 3 months? \\
\hline & BN4 & $\begin{array}{l}\text { Did you try to avoid weight gain by strict dieting or fasting, heavy } \\
\text { exercise, vomiting or using laxatives/diuretics? }\end{array}$ \\
\hline & BN5 & Did you feel as a failure if not slim with an ideal figure? \\
\hline \multirow[t]{3}{*}{ Previous eating disorders } & ED1 & Have you had, or been suspected of having, an eating disorder? \\
\hline & ED2 & Have you been treated for an eating disorder? \\
\hline & ED3 & Have you suffered from an eating disorder without seeking help? \\
\hline
\end{tabular}

Figure 1. Questionnaire items formulated according to the DSM-IV diagnostic criteria of ED.

The instrument Rating of Anorexia and $\mathrm{Bu}$ limia $(\mathrm{RAB})$ was used for the interviews ${ }^{12,13}$. RAB is a semi-structured instrument developed and validated in Sweden. The RAB is based on the Eating Disorder Examination ${ }^{14}$ and consists of more than 50 items covering a wide range of eating disorder symptoms, related psychopathology, and background variables. All information necessary to establish a DSM-IV diagnosis of an eating disorder is covered in the RAB. In addition to the RAB, weight and height charts were obtained from the school health service. All participants were interviewed by the same child psychiatrist experienced with patients suffering from eating disorders.

Diagnoses of eating disorders were set according to the DSM-IV criteria ${ }^{7}$. In addition to the diagnoses in the DSM-IV a subclinical eating disorder was diagnosed if the participant had dieted or binged, feared gaining weight or becoming fat, was fixated with body weight or shape, and evaluated him/herself strongly in terms of body weight or 
shape. The participant was able to eat normal meals, but not completely without reservation. To be diagnosed as subclinical the participant's weight loss or disturbed eating was not severe enough for a DSM-IV diagnosis. See A. Isomaa, Isomaa, Marttunen, KaltialaHeino \& Björkqvist ${ }^{15}$ for a more detailed description of the procedure and the criteria used in the study.

\section{Results}

One third $(29.5 \%)$ of the girls and $7.5 \%$ of the boys reported dieting or deliberately keeping a low weight, $\chi_{(1)}^{2}=47.48, p<$ 0.001 . Bingeing was reported by $11.1 \%$ of both girls and boys. Girls reported more eating disorder symptomatology in addition to dieting or bingeing than boys. Reporting at least one additional AN criterion in addition to dieting and thus qualifying for an interview was more common among girls than among boys, $\chi_{(1)}^{2}=8.01, p<0.01$. Dieting was among girls accompanied by at least one additional AN criterion in $84.1 \%$ of the girls and in $56.5 \%$ of the boys. Additional bulimic pathology was also more common among girls who binged than among boys, $\chi_{(1)}^{2}=17.13, p<$ 0.001 . Bingeing was accompanied by at least one additional $\mathrm{BN}$ criterion in $90.3 \%$ of the girls and in $41.2 \%$ of the boys. The most common compensatory behaviours were heavy exercise and fasting. None of the boys, but $38.7 \%$ of the girls reported vomiting to avoid weight gain after bingeing. Two participants reported using medications for purging. Girls also more often reported previous history of, suspicion of, or treatment for an ED than boys, $\chi_{(1)}^{2}=27.73, p<0.001$ (Figure 2). As a result of the self-reports, 69 girls and 13

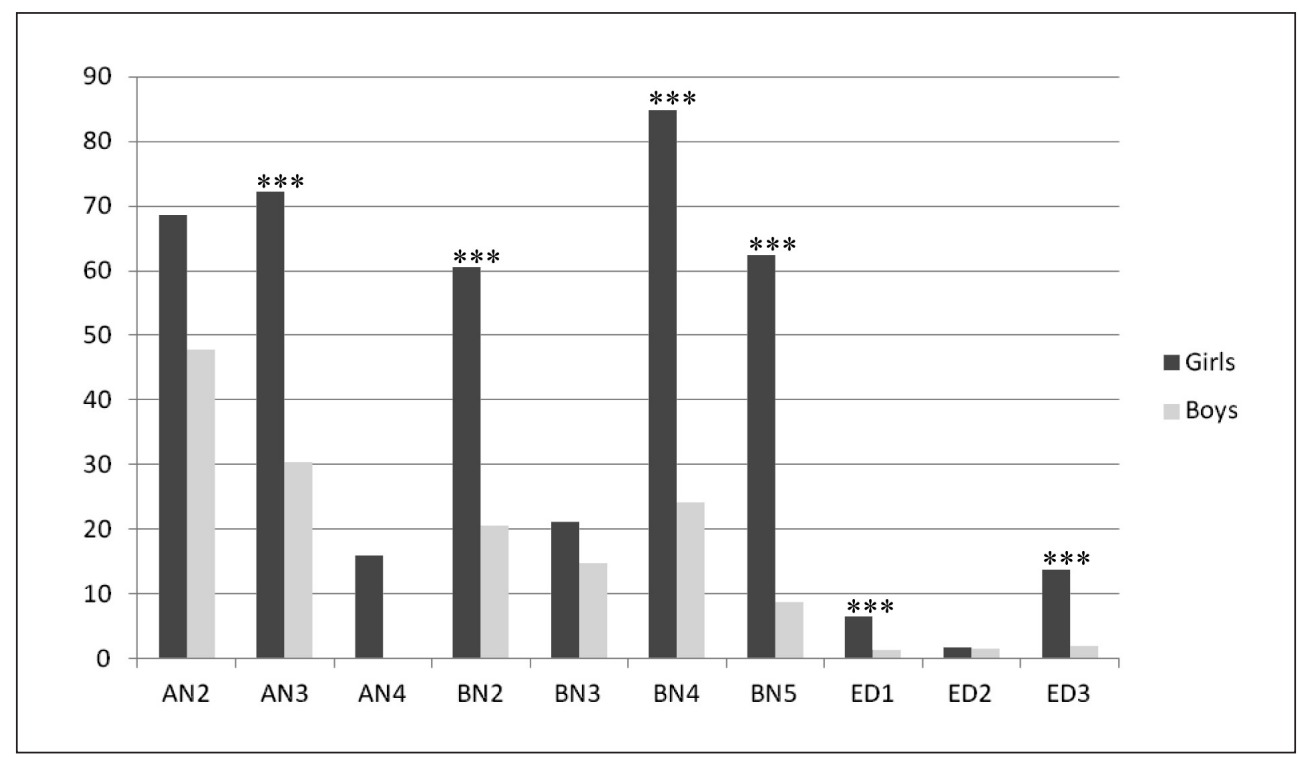

Note: See table 1 for explanations to abbreviations $* * * p<0.001$

Figure 2. Percentage of self-reported eating disorder symptoms in addition to dieting (AN2-4, $n=82$ girls and 13 boys), bingeing (BN2-5, $n=28$ girls and 14 boys), and ED history (ED1-3, $n=277$ girls and 305 boys). 
boys were invited to an interview for potential AN, 28 girls and 14 boys for potential $\mathrm{BN}$, and 49 girls and 13 boys for potential previous ED. Due to overlap the total number of girls and boys invited to an interview was 89 girls, of which 85 (94.4\%) participated and 37 boys, of which 28 (73.7\%) participated, $\chi_{(1)}^{2}=34.12, p<0.001$.

Since no case of DSM-IV eating disorders were found among the boys, further analyses were conducted only for girls. AN based on the self-report resulted in a positive predictive value (PPV) of $60.0 \%$ for lifetime and $20 \%$ for current eating disorder, when compared to the results in the RAB. If subclinical eating disorders were included the PPV was $90.0 \%$ for lifetime and $60.0 \%$ for current eating disorder. No case of $\mathrm{BN}$ was detected by the RAB, but self-reported $B N$ symptoms were predictive of both EDNOS and subclinical eating pathology. Self-report of being suspected of having an ED and having received treatment for an ED was also strongly predictive of a lifetime diagnosis of an ED (Tables 1 and 2). The self-reported ED symptoms which were the strongest predictors of a diagnosis of an ED was dieting accompanied by amenorrhoea, PPV for lifetime pathology $76.9 \%$ and current pathology $53.8 \%$, and bingeing accompanied by vomiting, PPV for lifetime pathology $75.0 \%$ and current pathology $41.7 \%$.

Self- or school health reported low weight (age-adjusted BMI $\leq 17.5^{19}$ ) was not a good indicator of an ED. Thirteen girls had a selfreported and seven girls a school health reported low weight, but none of these girls had an ED according to the RAB.

Table 1

$\mathrm{RAB}$ based lifetime eating disorders in relation to questionnaire based eating disorder symptoms, with corresponding positive predictive values (PPV), among girls

Number of self-reported symptoms Diagnosis confirmed by the interview

PPV

\begin{tabular}{|c|c|c|c|c|c|c|c|}
\hline & & $\begin{array}{c}\text { No ED } \\
\mathrm{n}(\%)\end{array}$ & $\begin{array}{c}\text { Subclinical } \\
\mathrm{n}(\%)\end{array}$ & $\begin{array}{c}\text { EDNOS } \\
\mathrm{n}(\%)\end{array}$ & $\begin{array}{c}\mathrm{AN} \\
\mathrm{n}(\%)\end{array}$ & $\begin{array}{c}\mathrm{BN} \\
\mathrm{n}(\%)\end{array}$ & $\%$ \\
\hline \multirow[t]{3}{*}{$\mathrm{AN}$} & 4 & $1(10.0)$ & $3(30.0)$ & $3(30.0)$ & $3(30.0)$ & - & 90.0 \\
\hline & 3 & $22(55.0)$ & $8(20.0)$ & $9(22.5)$ & $1(2.5)$ & - & 45.0 \\
\hline & 2 & $18(94.7)$ & - & $1(5.3)$ & - & - & 5.3 \\
\hline \multirow[t]{4}{*}{$\mathrm{BN}$} & 5 & $2(66.7)$ & $1(33.3)$ & - & - & - & 33.3 \\
\hline & 4 & $4(33.3)$ & $2(16.7)$ & $5(41.7)$ & $1(8.3)$ & - & 66.7 \\
\hline & 3 & $3(30.0)$ & $3(30.0)$ & $4(40.0)$ & - & - & 70.0 \\
\hline & 2 & $4(80.0)$ & $1(20.0)$ & - & - & - & 20.0 \\
\hline \multirow[t]{3}{*}{ ED } & Suspicion & $4(22.2)$ & $4(22.2)$ & $7(38.9)$ & $3(16.7)$ & - & 77.8 \\
\hline & Treatment & $1(20.0)$ & $3(60.0)$ & $1(20.0)$ & - & - & 80.0 \\
\hline & History & $18(47.4)$ & 7 (18.4) & $8(21.1)$ & $5(13.2)$ & - & 52.6 \\
\hline
\end{tabular}


Table 2

$\mathrm{RAB}$ based current eating disorders in relation to questionnaire based eating disorder symptoms, with corresponding positive predictive values (PPV), among girls

\begin{tabular}{|c|c|c|c|c|c|c|c|}
\hline & $\begin{array}{l}\text { Number of } \\
\text { self-reported } \\
\text { symptoms }\end{array}$ & Diagnosi & nfirmed by th & erview & & & PPV \\
\hline & & $\begin{array}{l}\text { No ED } \\
\mathrm{n}(\%)\end{array}$ & $\begin{array}{c}\text { Subclinical } \\
\mathrm{n}(\%)\end{array}$ & $\begin{array}{c}\text { EDNOS } \\
\mathrm{n}(\%)\end{array}$ & $\begin{array}{c}\text { AN } \\
\mathrm{n}(\%)\end{array}$ & $\begin{array}{c}\mathrm{BN} \\
\mathrm{n}(\%)\end{array}$ & $\%$ \\
\hline \multirow[t]{3}{*}{$\overline{\mathrm{AN}}$} & 4 & $4(40.0)$ & $4(40.0)$ & $1(10.0)$ & $1(10.0)$ & - & 60.0 \\
\hline & 3 & $29(72.5)$ & $8(20.0)$ & $3(7.5)$ & - & - & 27.5 \\
\hline & 2 & $18(94.7)$ & - & $1(5.3)$ & - & - & 5.3 \\
\hline \multirow[t]{4}{*}{$\mathrm{BN}$} & 5 & $2(66.7)$ & $1(33.3)$ & - & - & - & 33.3 \\
\hline & 4 & $6(50.0)$ & $4(33.3)$ & $1(8.3)$ & $1(8.3)$ & - & 50.0 \\
\hline & 3 & $9(90.0)$ & - & $1(10.0)$ & - & - & 10.0 \\
\hline & 2 & $5(100.0)$ & - & - & - & - & - \\
\hline \multirow[t]{3}{*}{$\overline{\mathrm{ED}}$} & Suspicion & $10(55.6)$ & $5(27.8)$ & $2(11.1)$ & $1(5.6)$ & - & 44.4 \\
\hline & Treatment & $2(40.0)$ & $2(40.0)$ & $1(20.0)$ & - & - & 60.0 \\
\hline & History & $25(65.8)$ & $9(23.7)$ & $2(5.3)$ & $2(5.3)$ & - & 34.2 \\
\hline
\end{tabular}

\section{Discussion}

The aim of the present study was to analyse the capacity of self-reported eating disorder symptoms to capture clinically significant eating disorders. As expected girls reported more eating disorder symptoms than boys. In general, the more symptoms reported by the adolescents the more likely was a clinically significant eating disorder. Self-reported symptoms were a better predictor of lifetime eating disorder symptomatology than current disorder status, which is expected from the formulation of the self-report questions. Since bulimic eating pathology was rare in the studied population results need to be interpreted with caution. Even though no case of $\mathrm{BN}$ was detected by the RAB, self-reported bulimic symptoms did predict other forms of eating pathology. Bingeing was as common among boys as among girls. The in- terviews did however reveal that misinterpretation of the concept of binge eating was frequent among boys and resulted in a many false positives. The reasons why we were not able to find any BN in the study might be related to the age of the participants ${ }^{18}$, the inability of the screening procedure to detect $\mathrm{BN}$ cases, or related to the size of the sample.

The strongest solitary predictors of eating disorders were amenorrhoea when dieting and vomiting as a compensatory behaviour. Also self-reports of receiving treatment for an eating disorder was highly predictive of eating pathology. The findings were in line with the study by Keski-Rahkonen and colleagues ${ }^{16}$. Self-report of having suffered from an eating disorder was not a good indicator of either lifetime or current eating disorder. This might seem odd, but in most cases the adolescents were not sure if they really had had a disorder. The difficulty in reliably reporting 
having suffered from an eating disorder might be related to the current diagnostic systems, which also fail to specify eating disorders ${ }^{9-11}$. The large proportion of unspecified eating disorders is potentially leading to vagueness of the whole eating disorder concept.

Self-reported eating disorder symptoms seem to be relatively good predictors of broadly defined eating pathology, but may result in overestimation of clinical conditions. The findings lend support to the idea that selfreports alone are not sufficient for epidemiological purposes ${ }^{5,17,18}$, but may be valuable tools for analysing clinical and societal correlates and concomitants of eating pathology.

\section{References}

1. Klump KL, Bulik CM, Kaye WH, Treasure J, Tyson E. Academy for eating disorders position paper: Eating disorders are serious mental illnesses. Int J Eat Disord 2009; 42: 97-103.

2. American Psychiatric Association. Practice guideline for the treatment of patients with eating disorders, 3rd ed. Washington, DC: APA; 2006.

3. Keski-Rahkonen A, Raevuori A, Hoek HW. Epidemiology of eating disorders: An update. In: Wonderlich S, Mitchell JE, de Zwaan M, Steiger H, editors. Annual review of eating disorders. Part 2. Oxford: Radcliffe Publishing Ltd; 2008. p. 58-68.

4. Mintz LB, O'Halloran MS, Mulholland AM, Schneider PA. Questionnaire for eating disorder diagnoses: Reliability and validity of operationalizing DSM-IV criteria into a self-report format. J Couns Psychol 1997; 44:63.

5. Jacobi C, Abascal L, Taylor CB. Screening for eating disorders and high-risk behavior: Caution. Int J Eat Disord 2004; 36: 280-295.

6. Patton GC, King MB. Epidemiological study of eating disorders: Time for a change of emphasis. Psychol Med 1991; 21:287.

7. American Psychiatric Association. Diagnostic and statistical manual of mental disorders. fourth edition, text revision. Washington, DC: American Psychiatric Association; 2000.

8. American Psychiatric Association. DSM-5 development; 2010.
9. Fairburn CG, Bohn K. Eating disorder NOS (EDNOS): An example of the troublesome "not otherwise specified" (NOS) category in DSM-IV. Behav Res Ther 2005; 43: 691-701.

10. Machado PP, Machado BC, Goncalves S, Hoek HW. The prevalence of eating disorders not otherwise specified. Int J Eat Disord 2007; 40: 212-217.

11. Isomaa R, Isomaa AL, Marttunen M, Kaltiala-Heino $\mathrm{R}$, Björkqvist $\mathrm{K}$.. The prevalence, incidence and development of eating disorders in Finnish adolescents: a two-step 3-year follow-up study. Eur Eat Disord Rev 2009; 17(3): 199-207.

12. Clinton D, Norring $C$. The rating of anorexia and bulimia (RAB) interview: Development and preliminary validation. Eur Eat Disord Rev 1999; 7: 362-371.

13. Nevonen L, Broberg AG, Clinton D, Norring C. A measure for the assessment of eating disorders: Reliability and validity studies of the rating of anorexia and bulimia interview - revised version (RAB-R). Scand J Psychol 2003; 44: $303-310$

14. Cooper Z, Fairburn CG. The eating disorder examination: A semi-structured interview for the assessment of the specific psychopathology of eating disorders. Int J Eat Disord $1987 ; 6$ : 1-8.

15. Isomaa $\mathrm{AL}$, Isomaa $\mathrm{R}$, Marttunen $\mathrm{M}$, Kaltiala-Heino R. Obesity and eating disturbances are common in 15-yearold adolescents. A two-step interview study. Nord J Psychiatry 2010; 64: 123-129.

16. Keski-Rahkonen A, Sihvola E, Raevuori A, Kaukoranta J, Bulik CM, Hoek HW, et al. Reliability of self-reported eating disorders: Optimizing population screening. Int J Eat Disord 2006; 39: 754-762.

17. Engström I, Norring C. Estimation of the population "at risk2 for eating disorders in a non-clinical swedish sample: A repeated measures study. Eat Weight Disord 2002; 7 : 45-52.

18. Hoek HW, van Hoeken D. Review of the prevalence and incidence of eating disorders. Int J Eat Disord 2003; 34 : 383-396.

19. Birgegård A, Norring C, Clinton D. DSM-IV versus DSM-5: implementation of proposed DSM-5 criteria in a large naturalistic database. Int J Eat Disord 2012; 45: 353-361.

Corresponding author:

Rasmus Isomaa, $\mathrm{PhD}$

Åbo Akademi University

Department of Social Sciences

P.O. Box 311, FI-65101 Vasa, Finland

Phone: +358 503521132

E-mail: rasmus.isomaa@abo.fi 